\title{
Fantasia Sul América para saxofone solo, processos de assimilação e incorporação de repertório
}

\author{
José de Carvalho Oliveira
}

Marco Tulio de Paula Pinto

Universidade Federal do Estado do Rio de Janeiro | Brasil

Resumo: Este trabalho evidencia processos de assimilação e incorporação de repertório entre instrumentos musicais análogos - o oboé e o saxofone, tendo como base a Fantasia Sul América para oboé solo, de Claudio Santoro (1983). Os procedimentos utilizados incluem entrevista com o saxofonista brasileiro Dílson Florêncio (2019) e uma breve revisão histórica em torno do IV Concurso Sul América de Música - Jovens Concertistas Brasileiros, realizado no Rio de Janeiro em 1985. Os resultados da pesquisa apontam significativa visibilidade da obra averiguada através da repercussão midiática na plataforma digital do YouTube, programas de recitais e a ampla divulgação de edições não oficiais da versão para saxofone a partir do manuscrito entre saxofonistas.

Palavras-chave: Fantasia Sul América. Repertório para Saxofone. Performance. Claudio Santoro.

\begin{abstract}
This work shows the assimilation and incorporation of repertoire between similar musical instruments: oboe and the saxophone, based on Fantasia Sul América for solo oboe, by Claudio Santoro (1983). The procedures used include an interview with the Brazilian saxophonist Dílson Florêncio (2019) and a brief historical review of the IV South America Music Competition - Young Brazilian Concertists, held in Rio de Janeiro in 1985. The research results point to significant visibility of the work ascertained through the media repercussion on the YouTube digital platform, recital programs and the wide dissemination of unofficial editions of the saxophone version from the manuscript among saxophonists.
\end{abstract}

Keywords: Fantasia South America. Repertoire for Saxophone. Performance. Claudio Santoro. 
$s$ transcriçóes de repertório por instrumentos, aos quais a obra não foi dedicada
originalmente, têm se tornado bastante comum. Um dos exemplos mais clássicos em
relação a esse tipo de procedimento ocorre com certa frequência entre obras originais para violino solo e outros instrumentos, sobretudo os de sopro, como por exemplo, a Partita de J.S. Bach (1720), tocada amplamente por flautistas. Entretanto, na situação da Fantasia Sul América para saxofone solo, de Claudio Santoro (1983), ocorre uma raridade na medida em que torna a obra incorporada mais conhecida pelo instrumento que a assimilou do que propriamente a versão original.

Para descrever esse curioso processo de assimilação e os meios pelos quais isso ocorreu, este trabalho apresenta uma breve contextualização em torno do IV Concurso Sul América de Música Jovens Concertistas Brasileiros (1985), destacando as circunstâncias que conduziram a incorporação da obra, originalmente escrita para oboé, ao repertório de saxofone.

Sobre a incorporação da obra ao repertório de saxofone, utilizaremos como base não apenas o relato do saxofonista Dílson Florêncio como também programas de recitais e concertos. No que se refere à notabilidade da versão para saxofone, como ferramenta, utilizaremos o impacto midiático em número de publicações e visualizações na plataforma de compartilhamento de vídeos do YouTube.

1. Fantasia Sul América para oboé solo, de Claudio Santoro (1983) e a reunião das Fantasias na Sinfonia № 12 (1987)

Dedicada ao oboísta Václav Vinecký, a Fantasia Sul América para oboé solo (Fig. 1), de Claudio Santoro (1983), é uma obra comissionada pela Cia. Sul América como peça de confronto para o I Concurso Sul América de Música - Jovens Concertistas Brasileiros de 1983, no Rio de Janeiro e, de acordo com Fraga (FRAGA, 2008, p. 22), o próprio compositor participou da banca. 
FIGURA 1 - Fantasia Sul América para oboé solo, Claudio Santoro (1983). Manuscrito.

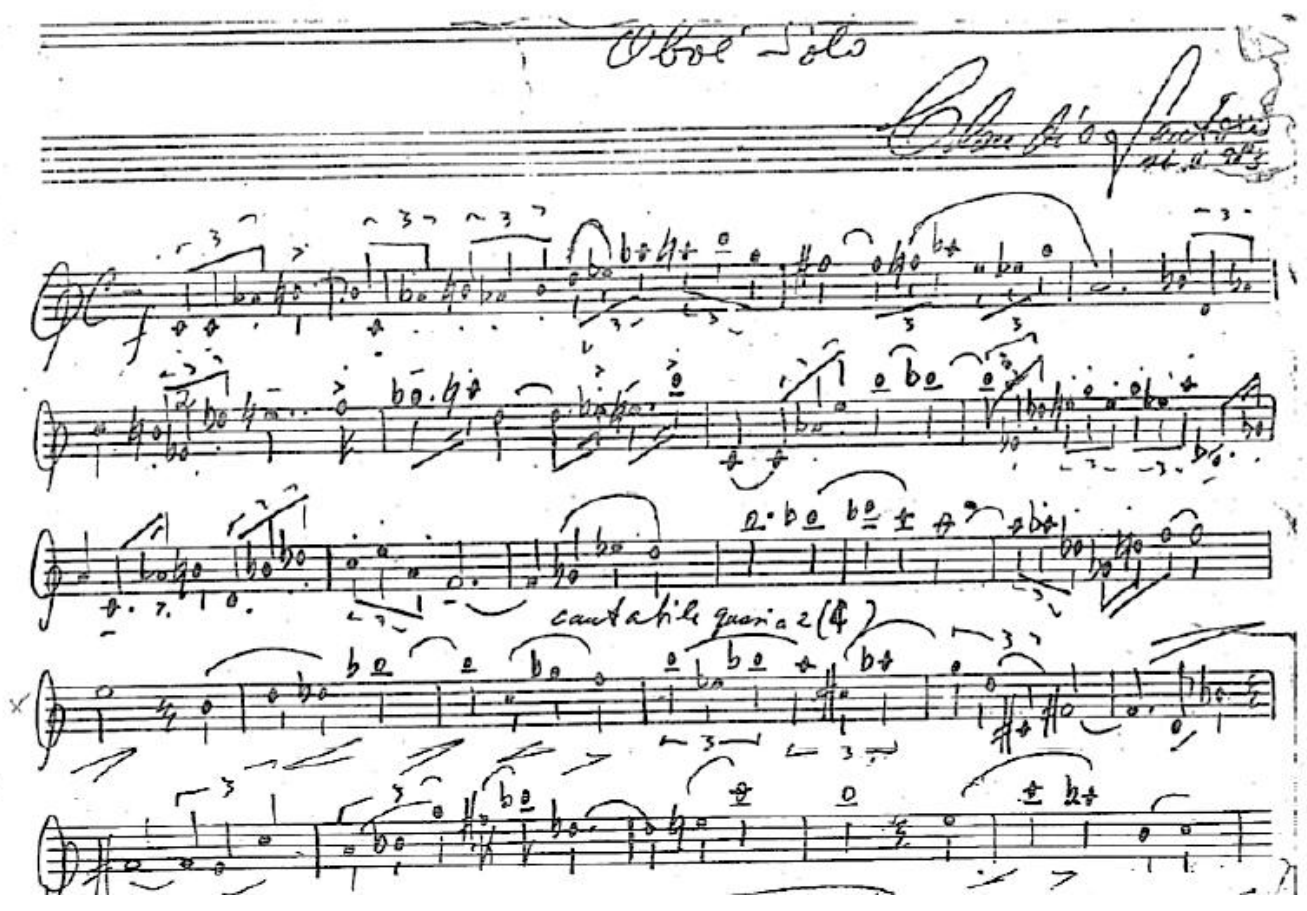

Fonte: Arquivo pessoal de Dílson Florêncio.

A Fantasia Sul América para oboé é também parte integrante de uma série de obras para instrumentos solistas e todas possuem o mesmo nome. Claudio Santoro compôs uma versão da Fantasia Sul América para todos os instrumentos de orquestra, além de piano e violão. As peças também possuem duas versóes e podem funcionar tanto como peça solo quanto como peça concertante, visto que todas possuem um acompanhamento orquestral, estruturado através de módulos que se interconectam de forma sequencial.

Pela notabilidade do Concurso Sul América de Música - Jovens Concertistas Brasileiros, realizado entre 1983-1985, as Fantasias tornaram-se peças prestigiadas entre professores e estudantes, configurando-se em objeto de pesquisa de inúmeros trabalhos acadêmicos.

Com relação à orquestração das Fantasias Sul América, no que viria ser a Sinfonia № 12 (1987), segundo nota do programa do concerto realizado pela Orquestra Sinfônica da Universidade de São Paulo (OSUSP) na Sala São Paulo, dia 2 de novembro de 2019, por ocasião da estreia mundial da obra (Fig. 2), Santoro escolheu obras específicas da série Fantasia Sul América e juntouas em diferentes movimentos representados pelos instrumentos - violino, viola, violoncelo, flauta, oboé, clarineta, trompete, trompa e trombone: 
[...] No final de maio (1983), Santoro terminaria uma versão de acompanhamento com orquestra para cada instrumento, de forma que os finalistas do concurso tivessem também a oportunidade de apresentar o "solo" com acompanhamento orquestral. (...) Santoro continuou modificando a obra e, em 1987, acrescentou mais uma Fantasia para trompa. Em sua última viagem à Europa no início de 1989, Santoro levou diversas obras na bagagem para serem revistas. Foi assim com a ópera Alma, com a $14^{a}$ Sinfonia e também com a 12 Sinfonia (Nota do programa de concerto da OSUSP, 2/11/2019).

FIGURA 2 - OSUSP - Programa de concerto da temporada 2019, 02 de novembro. Sala São Paulo, 2019.

\title{
Programa
}

02 de novembro de 2019

CATHERINE LARSEN-MAGUIRE, rOgôncia

\author{
SILVIA DE LUCCA (1960) \\ Em Memória (1993) 9 min \\ SERGEI RACHMANINOFF (1873-1943) \\ Concerto para Piano $\mathrm{N}^{\circ} 2$ \\ em Dó Menor Op.18 (1900) $33 \mathrm{~min}$ \\ 1. Moderato \\ II. Adagio sostenuto \\ III. Allegro scherzando \\ NAHIM MARUN, piano \\ INTERVALO \\ CLÁUDIO SANTORO (1919-1989) \\ In Tele Tonus Visionen (1967) $4 \mathrm{~min}$ \\ CLÁUDIO SANTORO (1919-1989) \\ Sinfonia $N^{\circ} 12$ (Estreia Mundial) $15 \mathrm{~min}$ \\ L. Andante-lento-andante \\ II. Allegro \\ III. Allegro-moderato-allegro \\ CLÁUDIO MICHELETTI, violino / ESTELA ORTIZ, viola \\ JULIO ORTIZ, violoncolo / RENATO KIMACHI, flauta \\ MATHEUS MINCZUK, ObOÓ / TIAGO JOSÉ GARCIA, clarinete \\ AMARILDO NASCIMENTO, trompoto / VITOR FERREIRA, trompa \\ CARLOS FREITAS, trombono

\section{Orquestra Sinfônica} \\ da Universidade de \\ São Paulo - OSUSP
}

Fonte: Arquivo pessoal de José de Carvalho Oliveira.

A Sinfonia № 12 está estruturada por módulos que se interconectam de forma sequencial possibilitando, assim, a execução de solistas intercalados na mesma orquestração. A inspiração para essa sinfonia concertante de Santoro, conforme relatado em parágrafos anteriores, surgiu da ideia de 
aproveitar e reunir as Fantasias em uma obra integralmente diferente, usando a base de orquestração que já tinha realizado, transferindo parte dos solos para orquestra e, assim, enriquecendo o diálogo entre solistas e tutti conforme observado na Figura 3.

FIGURA 3 - Parte de trompete em Dó - solo (c. 1-23). II movimento da Sinfonia № 12 - de Claudio Santoro (1987).

Os compassos de pausa representam as partes dos solos de trompete transferidos para orquestra.

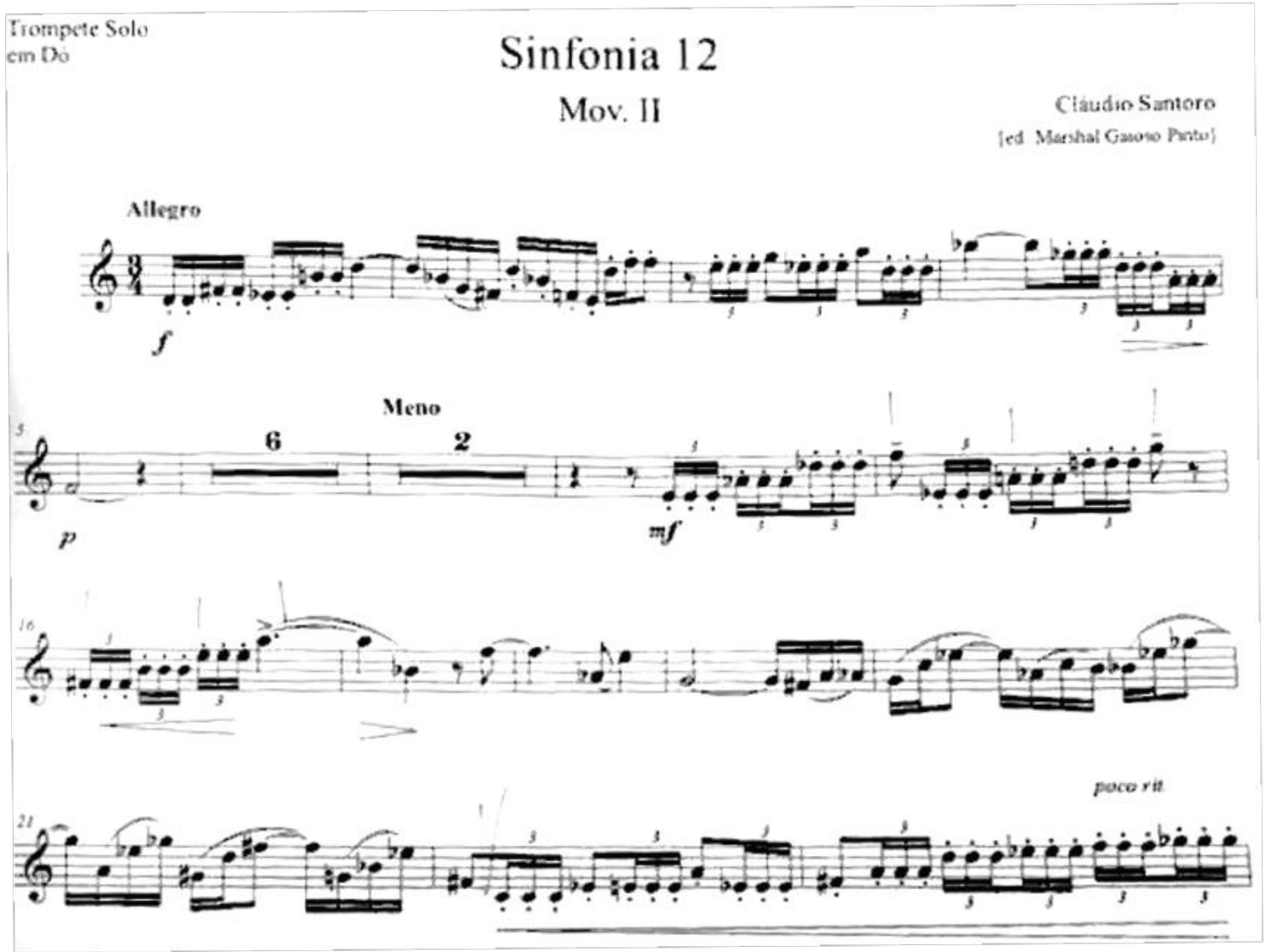

Fonte: Editora Savart, 1989 - ed. Marshal Gaioso Pinto.

Dessa forma, o primeiro movimento transformou-se em um concerto duplo de violoncelo e violino, seguido de um concerto duplo para clarineta e flauta, finalizando o primeiro movimento com a Fantasia para viola. O segundo movimento trata de uma elaboração da Fantasia Sul América para trompete, conforme visto na Figura 3. Já o terceiro e último movimento, Santoro inicia com a Fantasia Sul América para oboé (no manuscrito consta como módulo 6, Fig. 4), seguido da trompa, acrescentando ao final deste movimento mais uma Fantasia, a de trombone, estabelecendo a obra com 9 solistas. Infelizmente, porém, Claudio Santoro faleceu em março de 1989, sem ter escutado o resultado final de sua obra. 
FIGURA 4 - Módulo 6 - Manuscrito da Fantasia Sul América para oboé e acompanhamento orquestral, Claudio Santoro (1983). Protótipo do terceiro movimento da Sinfonia № 12 (1987).

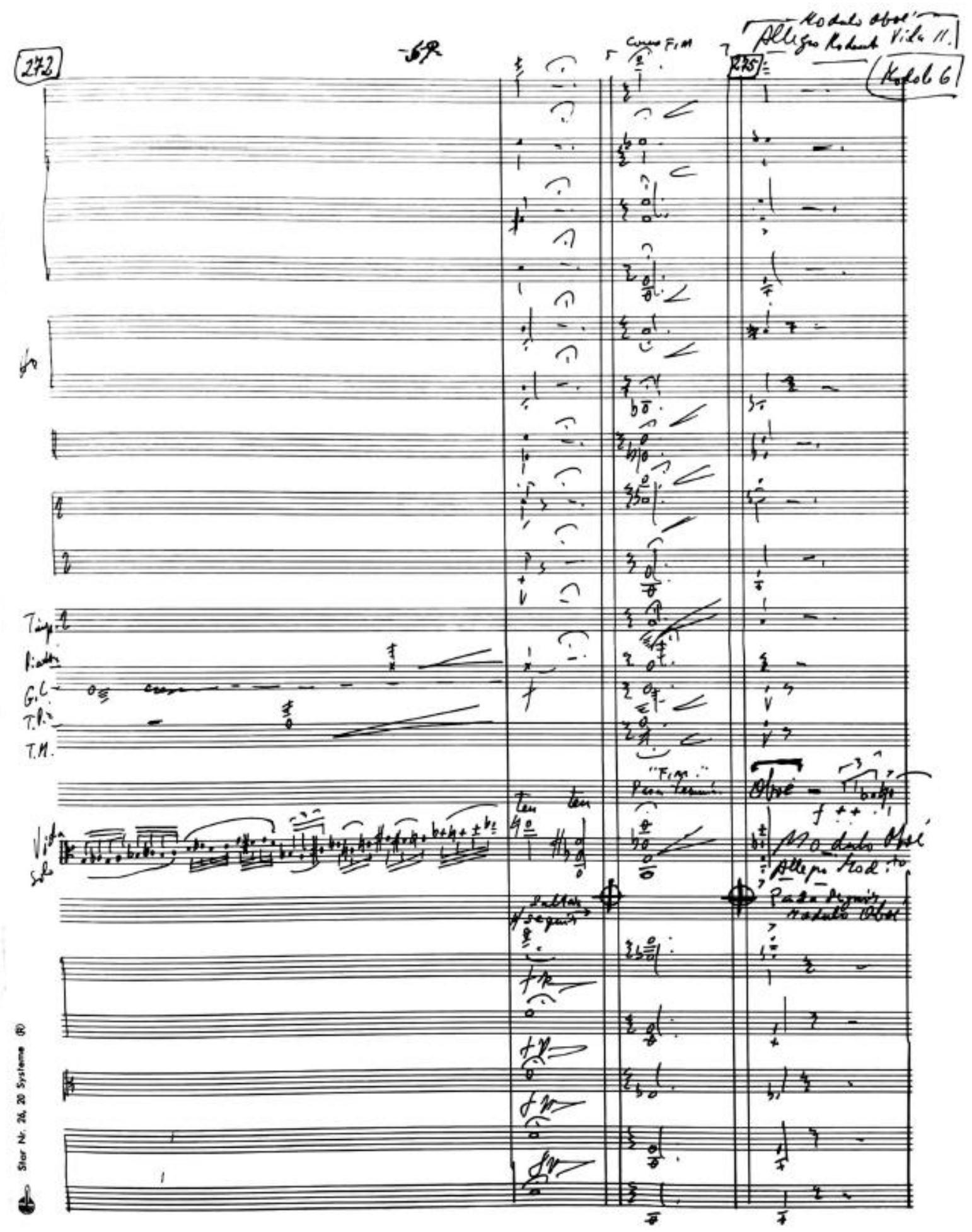

Fonte: Arquivo pessoal de José de Carvalho Oliveira. 


\section{O repertório brasileiro para saxofone}

Quanto à utilização do saxofone na música brasileira na segunda metade do século XX, especificamente na música de concerto, há de se considerar uma participação significativa do instrumento, sobretudo na obra de Villa-Lobos que, em parte, é responsabilizado pela difusão e ampliação do repertório para o saxofone compondo, em 1948, talvez a principal obra brasileira para o instrumento e a mais notável do repertório de saxofone soprano (OLIVEIRA, 2019, p. 118), a Fantasia para saxofone soprano e pequena orquestra, citada pelo pesquisador Thomas Lilley (1998) como a peça mais importante para o repertório do saxofone soprano:

De 1948 é, sem dúvida, o trabalho mais importante para o instrumento, saxofone soprano. Escrito para saxofone soprano, três trompas e cordas, a Fantasia contém muitas das características mais famosas do compositor brasileiro - ritmos nativos vigorosos, longas melodias lânguidas e o contraponto bachiano. Embora o trabalho tenha sido dedicado a Mule, ele nunca o realizou (LILLEY, 1998, p. 58, tradução nossa).

Outros brasileiros também compuseram para o instrumento, talvez não na mesma proporção quantitativa, mas com igual destaque. São exemplos o Concertino para saxofone alto e orquestra (1964) de Radamés Gnattali, Ibirá Guira Recê para saxofone e orquestra de Edmundo Villani-Côrtes (2001) e o Concertante para saxofone alto e orquestra de Mário Ficarelli (1999).

Embora significativo, o repertório para o instrumento na música brasileira de concerto ainda é pequeno se comparado ao repertório de instrumentos tradicionais da orquestra.

No tocante ao repertório de câmara, entre os compositores brasileiros que compuseram, considerando o saxofone como parte da instrumentação, destaca-se Francisco Braga - autor da primeira obra contendo o saxofone no contexto camerístico, Cantigas e danças de pretos para quarteto de saxofones (1905). A obra faz parte como música incidental do melodrama denominado "O Contratador de diamantes" (Catálogo da Exposição comemorativa do centenário do nascimento de Francisco Braga, 1968, p. 12) que, apesar de constar a indicação para quarteto de saxofones, 
recentemente confirmou-se tratar de um noneto para nove saxofones ${ }^{1}$. É de Braga também outra importante obra do repertório, o Diálogo sonoro ao luar para saxofone alto em Eb e Bombardino em C, publicado no VI Boletim Latino-Americano de Música de 1946.

No repertório constam também obras significativas como o Sexteto Mistico (1917), Noneto (1923) e Quatuor (1921) de Villa-Lobos, Valsa Triste (S/D), Remechendo (1943) e Brasiliana 7 (1956) de Radamés Gnattali, Fantasia (1983) de Ronaldo Miranda e Desafio VIIIbis (1968) de Marlos Nobre.

Com relação a obras para saxofone solo, o número é relativamente pequeno se comparado a obras concertantes e/ou camerísticas. Sob esse aspecto, enfocaremos a integração da Fantasia Sul América para oboé solo, de Claudio Santoro (1983), ao repertório de saxofone.

\section{A incorporação da Fantasia Sul América para oboé solo (1983) ao repertório de saxofone}

Concernente à pronta adaptação da escrita original para oboé ao idiomatismo do saxofone, é importante observar que, estruturalmente, o saxofone e o oboé têm a mesma conicidade e tessituras bastante parecidas. Tomando como base a escala geral dos sons, apenas uma nota os diferencia em extensão (Figura 5). Partindo da primeira nota da tessitura de cada instrumento, o oboé e o saxofone (sons escritos sem transposição) possuem como nota mais grave o Si bemol 2. Já como nota mais aguda, o oboé - Sol 5, enquanto o saxofone possui como nota mais aguda o Fá\# $5^{2}$.

\footnotetext{
${ }^{1}$ No catálogo de obras de Francisco Braga (2005), o título consta Cantigas e danças de pretos para quarteto de saxofones (1905), no entanto, o manuscrito encontrado por Oliveira (OLIVEIRA, 2019, p. 36) no arquivo da Banda Sinfônica do Corpo de Bombeiros do Rio de Janeiro em abril de 2018, possui parte para um noneto de saxofones, sendo 2 saxofones sopranos, 2 altos, 2 tenores, 2 barítonos e 1 sax baixo.

${ }^{2}$ Embora o saxofone tenha sua extensão natural de Si bemol 2 até Fá\# 5 (sons escritos), ao longo dos últimos anos, os fabricantes do instrumento vêm trabalhando para ampliação da extensão. No caso do soprano que é (geralmente) a voz mais aguda, a maioria da linha profissional possui uma chave adicional para alcançar o Sol 5, como, por exemplo, os fabricados pela Yanagisawa da série 991, bem como as equivalentes 992 - em bronze e 9930 - em prata. Das versóes modernas da Yanagisawa (sax soprano), apenas os modelos S-W01 e S-W02, não possuem a chave de Sol 5. Outras marcas como Yamaha - modelo Custon 875 EX HG, Selmer - Série III e outras de origem oriental como a Spina, também investiram na fabricação do soprano com a chave de Sol 5.
} 
FIGURA 5 - Tessitura do oboé (Si bemol 2 à Sol 5). Tessitura do saxofone (sons escritos - Si bemol 2 à Fá\# 5).

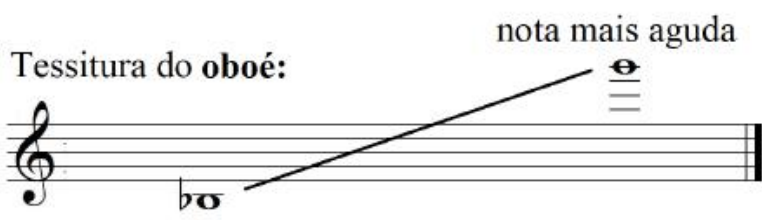

nota mais grave

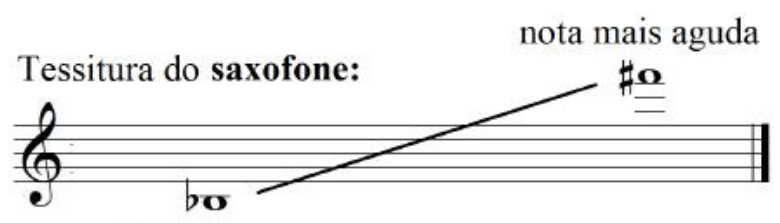

nota mais grave

Fonte: Editoração dos autores.

Ressalta-se ainda que por não existir literatura suficiente na época da criação do saxofone, é possível que se tenha utilizado, para o ensino desse instrumento, métodos de oboé (OLIVEIRA, 2019, p. 116). Na literatura didática do saxofone, ainda é utilizado métodos de oboé como, por exemplo, os 48 Estudos de W. Ferling (1946). Sobre a utilização de métodos de oboé para o ensino do saxofone na segunda metade do século XX, além dos benefícios, gerou também elementos contraproducentes à técnica como, o ensino equivocado da embocadura do saxofone igual à do oboé, como observado no método de saxofone Amadeu Russo: “(...) A boquilha introduz-se na boca com a palheta para baixo. Os lábios devem ser ligeiramente dobrados para dentro a fim de impedir que os dentes mordam a boquilha e influam sobre a qualidade do som (RUSSO, 2007, p. 3)”. O equívoco da informação contida no método Amadeu Russo ocorre em relação aos lábios cobrirem os dentes superiores e inferiores impedindo o contato com a boquilha quando, na verdade, a embocadura do saxofone se assemelha à de clarinete, ou seja, os dentes superiores se apoiam em contato direto sobre a boquilha, somente os lábios inferiores são dobrados sobre os dentes.

A partir das observaçóes acima e apesar das similaridades comentadas no que se refere aos princípios construtivos e processos de produção do som, o oboé e o saxofone possuem muitas diferenças também. Além da palheta dupla utilizada pelo oboé (na maioria dos casos, o oboísta é quem fabrica a sua própria palheta), as distinçôes vão desde a quantidade de ar necessário para obtenção do som à potência sonora.

Sobre o processo de incorporação da Fantasia Sul América para oboé solo ao repertório de 
saxofone, a primeira execução, foi do saxofonista brasileiro Dílson Florêncio ${ }^{3}$ em 1985, sugerida pelo próprio Claudio Santoro em um recital que antecedeu o IV Concurso Sul América de Música Jovens Concertistas Brasileiros de 1985. Na ocasião (FLORÊNCIO, 2019), o saxofonista, ainda aluno do Conservatório Nacional Superior de Música de Paris, manifestou interesse em participar do concurso, mas como não havia peças brasileiras para saxofone suficientes para todas as fases desse concurso, foi conversar pessoalmente com o compositor Claudio Santoro que, ao invés de escrever uma nova composição, sugeriu a Fantasia Sul América para oboé pela similaridade de tessitura.

(...) Fui aluno da Universidade de Brasília onde o Claudio Santoro também era professor. Estudei na França entre 1983 e 1987, nesse intervalo vinha sempre ao Brasil nas férias. Em 85 fui fazer o concurso Sul América no Rio de Janeiro, o repertório para o concurso exigia música brasileira. Como o repertório de saxofone possui poucas obras, eu e o Gonzaguinha (que foi meu Professor na UNB), conversando com ele sobre repertório, ele propôs: "vamos pedir para o Santoro escrever uma peça? Ele já escreveu para oboé, vamos pedir para ele escrever uma para saxofone”. Desta forma, para reforçar o pedido, o Gonzaguinha sugeriu que fossemos juntos conversar com o Santoro. Em seguida fomos até a sala do Santoro e fizemos o pedido, e ele, na mesma hora, no mesmo momento disse, "não precisa nem escrever, tem uma peça que eu fiz para oboé que vai ficar muito boa para o saxofone". Perguntei a ele, em qual saxofone, se a peça é para oboé, é no saxofone soprano? Ele respondeu, "não-não, no sax alto, você vai tocar as mesmas notas escritas para o oboé, exatamente, sem transportar", foi isso que aconteceu. Fiz um recital em Brasília como preparatório para o Concurso Sul América de Música - Jovens Concertistas Brasileiros de 85, no Rio de Janeiro e o Santoro foi assistir a estreia da obra ao saxofone alto. (Sobre a edição), o Gonzaguinha disse que não precisava editar, era só trocar de oboé para sax alto (FLORÊNCIO, 2019).

Conforme relato, Florêncio interpretou a obra já como "Fantasia Sul América para saxofone solo" em um recital do Duo Exótico com a pianista Maria Emília Osório pelo Projeto Terças Musicais 85, em agosto de 1985, na sala Funarte em Brasília, de acordo com o registro no programa do recital (Fig. 6).

\footnotetext{
${ }^{3}$ Informaçôes obtidas em entrevista com Dílson Florêncio em 28/10/2019. Formato da entrevista, aberta. Dílson Afonso Ferreira Florêncio é Professor de saxofone na Universidade Federal da Paraíba - UFPB.
} 
FIGURA 6 - Programa de recital - Terças Musicais 85. Duo Exótico (saxofone e piano); Dilson Florêncio e Maria Emília Osório. Brasília, 6 de agosto de 1985.

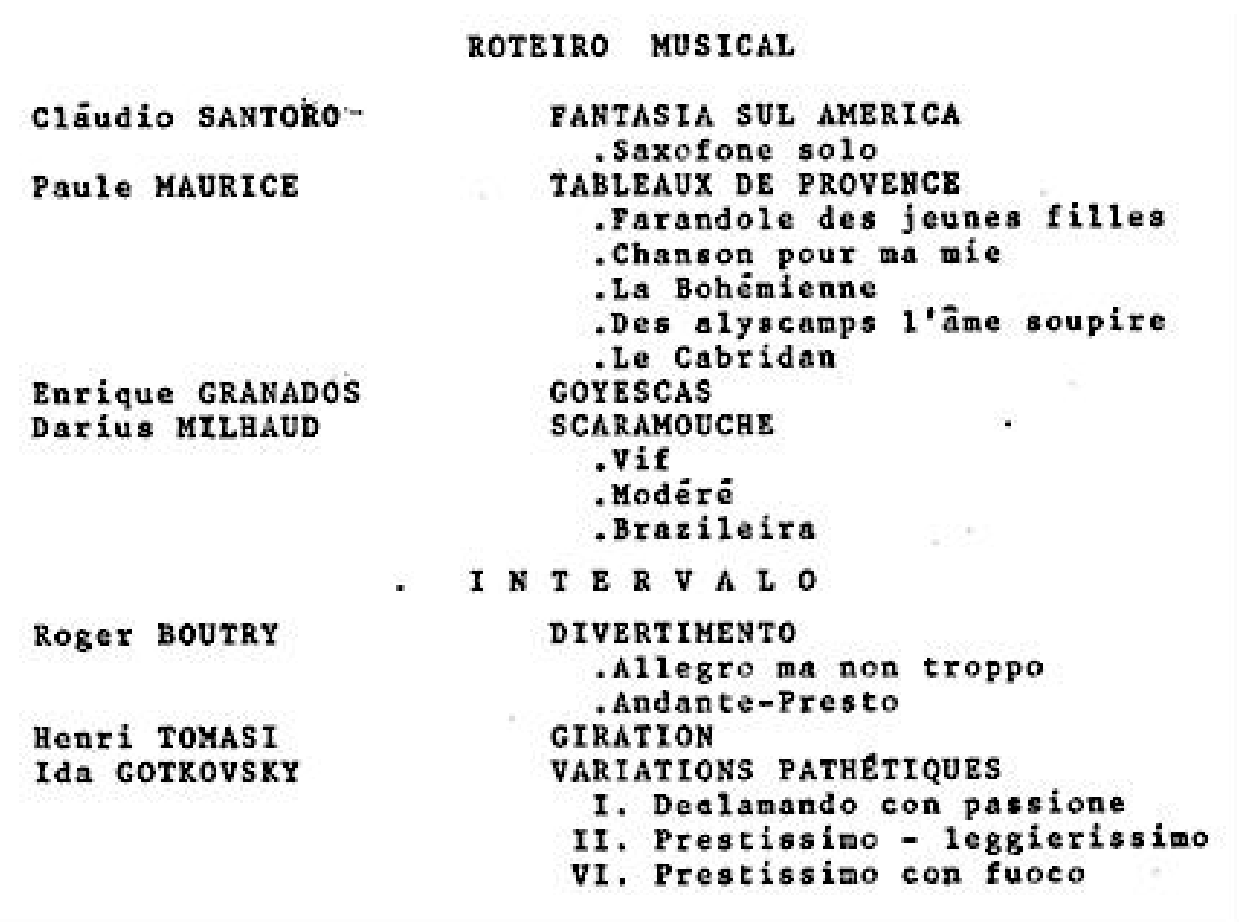

Fonte: Arquivo pessoal de Dílson Florêncio.

Segundo Florêncio (2019), Claudio Santoro se mostrou muito satisfeito com o resultado da performance da obra ao saxofone e, por isso, sugeriu ao saxofonista que a peça, a partir de então, pudesse ser adotada também como "Fantasia Sul América para saxofone solo". No entanto, conforme menciona Florêncio (2019), a obra não chegou a ser publicada oficialmente para saxofone; houve apenas uma pequena alteração a caneta na partitura feita pelo professor Gonzaguinha.

[...] A obra não foi publicada para saxofone, já que era a mesma de oboé. E, como eu ainda estava morando fora do país e só retornei 2 anos depois e, quando retornei fui deixando pra depois, pra depois, e findou que o Santoro faleceu antes de editar a obra também para saxofone (FLORÊNCIO, 2019).

Apesar de não ter sido publicada oficialmente por uma das editoras que trabalha com a obra de Claudio Santoro, talvez por isso, ao longo dos anos, surgiram algumas ediçôes não oficiais, firmando-se como a mais utilizada, a edição de Pinto, sendo a última atualização de 2019, conforme mostra a Figura 7. 
FIGURA 7 - (c.1-16) Fantasia Sul América para saxofone solo - Claudio Santoro (1983).

\section{Fantasia Sul América \\ para saxofone solo}
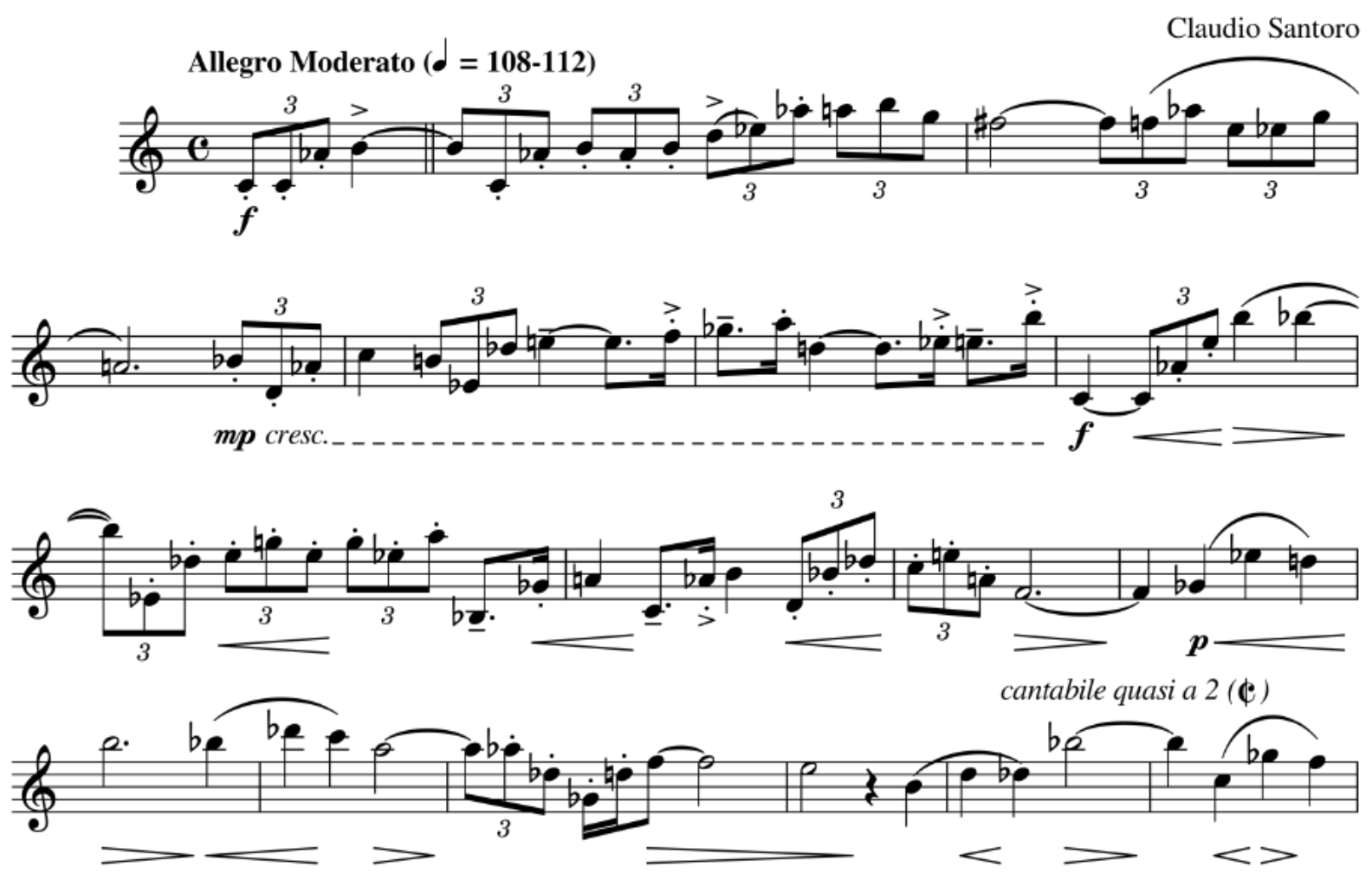

Fonte: Edição de Marco Tulio de Paula Pinto, MuseScore, Rio de Janeiro, 2019.

Como a Fantasia Sul América para saxofone não foi publicada oficialmente no catálogo de obras do compositor (SANTORO, 2019), consta o Choro Concertante para Saxofone Tenor e Orquestra (1951) como a única composição escrita por Claudio Santoro para o instrumento como solista. No entanto, apesar de pequena a produção de Claudio Santoro para o saxofone como instrumento solista (duas obras apenas), o concerto dedicado ao saxofone tenor e a Fantasia Sul América para saxofone solo conferem importante reconhecimento para o repertório, junto às composições de Villa-Lobos e Radamés Gnattali.

Acerca dos instrumentistas vencedores do IV Concurso Sul América de Música - Jovens Concertistas Brasileiros de 85, o saxofonista Dílson Florêncio figurou entre os cinco vencedores juntamente com o clarinetista Sérgio Burgani, Ivani Cardoso (piano), Beatriz Salles (flauta) e Radegundis Feitosa (trombone). 


\section{Visibilidade, interesse e popularidade: visualizações e publicações na plataforma digital do YouTube}

Para averiguar a repercussão midiática comparando visibilidade, interesse e execuções da obra entre as versões da Fantasia para oboé e saxofone, além de programas de recitais, utilizamos como referência o número de publicações e visualizações na plataforma digital de compartilhamento de vídeos enviados pelos usuários através da internet para o YouTube. A escolha e a utilização do YouTube como ferramenta de averiguação da popularidade da Fantasia Sul América nas versóes para oboé e saxofone deu-se pela ausência de gravações em outras plataformas digitais de compartilhamento de vídeos, como, por exemplo, o Spotify, um dos aplicativos pioneiros no mercado especializado em streaming de música.

Em relação aos procedimentos utilizados para localização dessas gravações no YouTube, foram realizadas buscas a partir da digitação do título da obra na versão para oboé, e depois para saxofone. Como resultado, na versão para oboé, a pesquisa apurou a existência de apenas uma gravação, a do oboísta estadunidense radicado no Brasil, Harold Emert ${ }^{4}$, publicado em 01/07/2020. Já a versão para saxofone, possui 11 publicaçóes (11 vídeos de diferentes intérpretes) somando um total de 12.524 visualizações entre o ano da primeira publicação (2010) até a data do término deste trabalho, conforme demonstrado no Quadro 1.

QUADRO 1 - Lista de publicações e visualizações da Fantasia Sul América para saxofone solo na plataforma digital do YouTube.

\begin{tabular}{ccccc}
\hline Intérprete & \multicolumn{1}{c}{ Link } & Views & $\begin{array}{c}\text { Ano de } \\
\text { Publicação }\end{array}$ & UF \\
\hline Marcos Silva & $\underline{\text { https://youtu.be/AmqeUSr9ULM }}$ & 1.313 & 2010 & $\mathrm{DF}$ \\
Michel Nirenberg & $\underline{\text { https://youtu.be/j38k6QHw8C0 }}$ & 499 & 2012 & $\mathrm{RJ}$ \\
Felipe Amorim & $\underline{\text { https://youtu.be/rXW2YrRJNJk }}$ & 875 & 2013 & $\mathrm{RJ}$ \\
Roger Cristiano & $\underline{\text { https://youtu.be/10KXVfc1Vms }}$ & 191 & 2014 & $\mathrm{~PB}$ \\
Douglas Braga & $\underline{\text { https://youtu.be/Kb_Z_IxSip8 }}$ & 2.635 & 2015 & $\mathrm{MG}$ \\
José de Carvalho & $\underline{\text { https://youtu.be/Yw0dksobumk }}$ & 2.017 & 2015 & $\mathrm{SP}$ \\
\hline
\end{tabular}

Fonte: Elaborado por esta pesquisa com base nos dados colhidos no YouTube em 31/07/2020.

\footnotetext{
4 Fantasia Sul América para oboé solo, Claudio Santoro. Interpretação de Harold Emert. Disponível em: $<$ https://www.YouTube.com/watch?v=9E96pLPxnOg> -82 visualizações. Acessado em 31/07/2020.
} 
OILIVEIRA, José de Carvalho; PINTO, Marco Tulio de Paula. Fantasia Sul América para saxofone solo, processos de assimilação e incorporação de repertório. Revista Vórtex, Curitiba, v.8, n.2, p. 1-16, 2020.

QUADRO 1 (cont.) - Lista de publicações e visualizações da Fantasia Sul América para saxofone solo na plataforma digital do YouTube.

\begin{tabular}{clccc}
\hline Intérprete & Link & Views & $\begin{array}{c}\text { Ano de } \\
\text { Publicação }\end{array}$ & UF \\
\hline David Peña & $\underline{\text { https://youtu.be/ywqqkFhw1Ck }}$ & 2.705 & 2016 & $\mathrm{SP}$ \\
Cesar Naves & $\underline{\text { https://youtu.be/8q58xOLrzTE }}$ & 133 & 2016 & $\mathrm{~PB}$ \\
Jonatas Weima & $\underline{\text { https://youtu.be/k1vkx-VTuBM }}$ & 70 & 2016 & $\mathrm{RJ}$ \\
Jônatas Silveira & $\underline{\text { https://youtu.be/VtrfINwdGxE }}$ & 2011 & 2019 & $\mathrm{~PB}$ \\
Marcos Paulo & $\underline{\text { https://youtu.be/9m-2w0h_wyY }}$ & 75 & 2019 & Não localizado \\
\hline
\end{tabular}

Fonte: Elaborado por esta pesquisa com base nos dados colhidos no YouTube em 31/07/2020.

Referente ao local das gravaçóes, os dados apresentados indicam que todas as execuçôes publicadas na plataforma do YouTube, foram realizadas em território brasileiro, notabilizando-se o ano de 2016 com o maior número de publicaçóes: três no total, justificado, talvez, pela ampla divulgação da Fantasia Sul América para saxofone como uma das peças de confronto exigidas na primeira etapa do I Concurso Internacional de Saxofone Dílson Florêncio realizado no ano de 2015 em Brasília 5 .

\section{Considerações finais}

No tocante à assimilação da Fantasia Sul América para oboé ao repertório de saxofone, o processo é muito similar às situações de aproveitamento de repertório, porém, neste caso, a obra não foi aproveitada aleatoriamente. O processo de assimilação ocorreu por sugestão do próprio compositor, conforme descreve Florêncio (2019), fato que torna a obra também opcional para saxofone.

O grau de importância da Fantasia Sul América dentro do repertório de saxofone no Brasil pode ser aferido pela constante participação da obra em programas de recitais, presença em currículos dos cursos de bacharelado em saxofone e também cumprindo sua primeira função como peça de concurso. Nos últimos dois concursos para sargentos músicos do Corpo de Fuzileiros

\footnotetext{
${ }_{5}^{5}$ Disponível em: <https://pt-br.facebook.com/pages/category/Music-Award/Concurso-Internacional-De-SaxofoneDilson-Flor\%C3\%AAncio-382028745318907/>. Acesso em 12/11/2019.
} 
Navais da Marinha do Brasil ${ }^{6}$, certames de 2019 e 2020, a Fantasia Sul América consta como obra de confronto para os candidatos à vaga de saxofone alto, além de ter sido utilizada também como uma das peças de confronto exigidas em uma das etapas do I Concurso Internacional de Saxofone Dílson Florêncio em 2015 na cidade de Brasília.

\section{REFERÊNCIAS}

BOLETIM LATINO-AMERICANO DE MÚSICA, vol. VI., primeira parte, Montevideo: Instituto Interamericano de Musicologia, abril de 1946. pp. 283-300.

BRAGA, Francisco. Catálogo da Exposição Comemorativa do Centenário do Nascimento de Francisco Braga (1868-1945). Rio de Janeiro: Biblioteca Nacional, 1968.

FERLING, W. 48 Études. Paris: Alphonse Leduc, 1946.

FLORÊNCIO, Dílson. Entrevista de José de Carvalho Oliveira em 28/10/2019. São Paulo. Registro em áudio.

FRAGA, Vinícius de Sousa. Estudo Interpretativo sobre a Fantasia Sul América para clarineta solo de Claudio Santoro. 2008. Dissertação de Mestrado em Música - Execução (clarineta) - Escola de Música, UFBA, Salvador, 2008.

OLIVEIRA, José de Carvalho. Fantasia para saxofone soprano e pequena orquestra, de Villa-Lobos (1948): aspectos contextuais e análise estrutural do primeiro movimento. 2019. Dissertação (Mestrado em Musicologia) - Escola de Comunicações e Artes, Universidade de São Paulo, São Paulo, 2019.

LYLLEY, Thomas. The repertoire heritage. In: INGHAM, Richard (Ed.). The Cambridge companion to the saxophone. Cambridge: Cambridge Press, 1998, p. 52-64.

RUSSO, Amadeu. Método Completo de Saxofone. São Paulo: Irmãos Vitale, 2007.

SANTORO, Claudio. Catálogo de obras de Claudio Santoro. Brasília: Associação Cultural Claudio Santoro, 2019. Disponível em:

http://www.claudiosantoro.art.br/Santoro/catalogo_geral_lista.html . Acesso em: 18/10/2019.

. Fantasia Sul América para oboé solo. Partitura. Brasília: manuscrito, 1983.

. Fantasia Sul América para saxofone solo. Partitura. Rio de Janeiro: MuseScore (Marco Tulio de Paula Pinto, 2019), 1983.

\footnotetext{
${ }^{6}$ Edital 2019. Disponível em:

$<$ https://www.inscricao.marinha.mil.br/marinhafn/Edital\%20Retificado.pdf?id file=965 $>$. Acesso em 10/01/2020 Edital 2020. Disponível em: <http://www.in.gov.br/web/dou/-/edital-de-19-de-fevereiro-de-2020-convocacao-para-oconcurso-de-admissao-ao-curso-de-formacao-de-sargentos-musicos-do-corpo-de-fuzileiros-navais-em-2021244620096>. Acesso em 11/01/2020
} 


\section{SOBRE OS AUTORES}

José de Carvalho Oliveira: Possui mestrado com pesquisa apoiada pela agência de fomento CAPES, sob orientação do Prof. Dr. Paulo de Tarso Salles, na área de Teoria e Análise Musical pela Universidade de São Paulo - ECA/USP (2019). É formado em Licenciatura em Música pelo Centro Universitário Sant'Anna e desde 2017 integra o corpo docente na referida instituição. É Professor do bacharelado em saxofone clássico/erudito no Centro Universitário Ítalo Brasileiro SP. Como pesquisador, possui trabalhos publicados no campo da Performance, Teoria, Análise Musical e Educação Musical. Como saxofonista dedica-se ao repertório brasileiro e contemporâneo. Currículo Lattes: http://lattes.cnpq.br/2051026202284367. ORCID: $\quad$ https://orcid.org/0000-0002-6803-6013..$\quad$ E-mail: josedecarvalhosax@gmail.com

Marco Tulio de Paula Pinto: Possui graduação em Bacharelado em Música/Instrumento: Saxofone, pela Universidade Federal do Rio de Janeiro (2002), mestrado em Música pela Universidade Federal do Estado do Rio de Janeiro (2005), na área de Práticas Interpretativas; Doutorado em Música pela Universidade Federal do Estado do Rio de Janeiro (2011), na área de Teoria e Prática da Interpretação. Exerce o cargo de professor associado de saxofone na UNIRIO Universidade Federal do Estado do Rio de Janeiro. Tem experiência na área de Artes, com ênfase em Interpretação Musical. Currículo Lattes: http://lattes.cnpq.br/8183951867136655. ORCID: https://orcid.org/0000-0003-15874176. E-mail: $\underline{\text { mtuliosax@gmail.com }}$ 